\title{
Nanobodies As Tools to Understand, Diagnose, and Treat African Trypanosomiasis
}

\begin{abstract}
Benoit Stijlemans ${ }^{1,2 *}$, Patrick De Baetselier ${ }^{1,2+}$, Guy Caljon ${ }^{3}$, Jan Van Den Abbeele ${ }^{4}$, Jo A. Van Ginderachter ${ }^{1,2}$ and Stefan Magez ${ }^{1,5}$

${ }^{1}$ Laboratory of Cellular and Molecular Immunology, Vrije Universiteit Brussel (VUB), Brussels, Belgium, ${ }^{2}$ Myeloid Cell Immunology Lab, VIB-UGent Center for Inflammation Research, Ghent, Belgium, ${ }^{3}$ Laboratory of Microbiology, Parasitology and Hygiene (LMPH), University of Antwerp (UA), Antwerp, Belgium, ${ }^{4}$ Unit of Veterinary Protozoology, Department of Biomedical Sciences, Institute of Tropical Medicine Antwerp (ITM), Antwerp, Belgium, ${ }^{5}$ Laboratory for Biomedical Research, Ghent University Global Campus, Incheon, South Korea
\end{abstract}

\section{OPEN ACCESS}

Edited by:

Colin Roger MacKenzie,

National Research

Council, Canada

Reviewed by:

Toya Nath Baral,

Merck Pharmaceuticals,

United States

Raffael Nachbagauer,

Icahn School of Medicine at

Mount Sinai, United States

*Correspondence:

Benoit Stijlemans

benoit.stijlemans@vub.be

'The first two authors' share coauthorship.

Specialty section:

This article was submitted to

Vaccines and Molecular

Therapeutics,

a section of the journal

Frontiers in Immunology

Received: 29 April 2017 Accepted: 08 June 2017

Published: 30 June 2017

Citation:

Stijlemans B, De Baetselier P, Caljon G, Van Den Abbeele J, Van Ginderachter JA and Magez S

(2017) Nanobodies As Tools to

Understand, Diagnose, and Treat

African Trypanosomiasis.

Front. Immunol. 8:724.

doi: 10.3389/fimmu.2017.00724 in humans and livestock and significantly affect the economic development of subSaharan Africa. Due to an elaborate and efficient (vector)-parasite-host interplay, required to complete their life cycle/transmission, trypanosomes have evolved efficient immune escape mechanisms that manipulate the entire host immune response. So far, not a single field applicable vaccine exists, and chemotherapy is the only strategy available to treat the disease. Current therapies, however, exhibit high drug toxicity and an increased drug resistance is being reported. In addition, diagnosis is often hampered due to the inadequacy of current diagnostic procedures. In the context of tackling the shortcomings of current treatment and diagnostic approaches, nanobodies (Nbs, derived from the heavy chain-only antibodies of camels and llamas) might represent unmet advantages compared to conventional tools. Indeed, the combination of their small size, high stability, high affinity, and specificity for their target and tailorability represents a unique advantage, which is reflected by their broad use in basic and clinical research to date. In this article, we will review and discuss (i) diagnostic and therapeutic applications of $\mathrm{Nbs}$ that are being evaluated in the context of African trypanosomiasis, (ii) summarize new strategies that are being developed to optimize their potency for advancing their use, and (iii) document on unexpected properties of Nbs, such as inherent trypanolytic activities, that besides opening new therapeutic avenues, might offer new insight in hidden biological activities of conventional antibodies.

Keywords: nanobody, diagnosis, treatment, African trypanosomes, paratransgenesis

\section{INTRODUCTION}

African trypanosomiasis (AT), caused by strictly extracellular unicellular flagellated protozoan parasites belonging to the genus Trypanosoma, is a "neglected" disease of medical and veterinary importance that significantly affects the socioeconomic development of sub-Saharan Africa (1-5). Hereby, AT affects mainly remote rural areas with minimal health infrastructure and its distribution coincides mostly with the habitat of the hematophagous insect vector, i.e., the tsetse fly (Glossina sp.) (6). In humans, the disease is known as human African trypanosomiasis (HAT) or sleeping sickness,
African trypanosomes are strictly extracellular protozoan parasites that cause diseases 
and is caused by (i) Trypanosoma brucei gambiense (Western and central Africa) which is an anthroponotic disease with a minor role for animal reservoirs accounting for $98 \%$ of the reported HAT cases, and causing a chronic, gradually progressing disease with limited symptoms, whereby the late meningoencephalitic stage is reached after months/years of infection (7-9), and (ii) Trypanosoma brucei rhodesiense (Eastern/southern Africa) which is a zoonotic disease affecting mainly animals (livestock and wildlife), with humans being only occasionally infected, and representing $2 \%$ of the reported HAT cases, whereby the infections are more acute and virulent/lethal with a rapid progression (within weeks) to the late meningoencephalitic stage (3, 9-12). Hence, the zoonotic nature of T. $b$. rhodesiense infections makes them more difficult to control compared to T. $b$. gambiense infections $(8,13,14)$. Animal African trypanosomiasis (AAT) or Nagana is the second form of AT affecting sub-Saharan Africa, which is mainly caused by Trypanosoma congolense, Trypanosoma vivax, and to a lesser extent Trypanosoma brucei brucei, whereas Surra and Dourine are also forms of AAT caused by Trypanosoma evansi and Trypanosoma equiperdum, respectively (15-17). Overall, T. congolense is a major constraint for livestock production in sub-Saharan Africa, whereby cattle succumb to infection primarily due to parasite-induced anemia or complications resulting from secondary, opportunistic infections (18). In addition, the estimated annual losses associated with AAT are about US\$5 billion $(1,19-21)$, which is mainly due to a combined result of political, sociocultural, environmental, entomological, and livestock management factors (22-24). So far, chemotherapy is the only strategy available to treat the disease, whereby unique organelles of trypanosomes (glycosomes or kinetoplast) that are absent in the mammalian host or trypanosome metabolic pathways that differ from their host counterparts (carbohydrate metabolism, protein and lipid modifications, and programmed cell death) are targeted (25-27). Given that chemotherapy is associated with high drug toxicity, there is an urgent need to optimize trypanocide usage and delivery in order to decrease the risk of toxicity and/or resistance development (28-30). Control of AT is also hampered due to inefficient diagnosis of the infection especially for AAT and T. $b$. rhodesiense HAT where microscopical parasite detection (cheap but with low sensitivity), detection of the parasite's DNA (expensive but with high sensitivity), or anti-parasite antibodies remain the only available tools for diagnosis. Yet, these techniques require specialized equipment and personnel and hence are not suitable for direct use in the field. Only for T. $b$. gambiense, monitoring tools are available for both detection and staging of the disease (4, 31-33). Existing field applicable antibody-based diagnostic tests still suffer from a lack of positive predictive value and cannot differentiate between active or cured infections $(32,34,35)$. Direct diagnosis aimed at parasite antigen detection is often hampered by sequestration of parasite antigens by the host's antibodies or by concealing of epitopes from the diagnostic monoclonal antibodies (mAbs) (36). Although immunodiagnostics based on antigen detection would be preferable, they are currently not available for trypanosomiasis in the field (32).

In contrast to conventional antibodies, nanobodies [Nbs or VHHs, i.e., camelid-derived single-domain antibody fragments $(\sim 15 \mathrm{kDa})$ that are selected through phage display technology and panning methodologies] $(37,38)$ could be used to overcome certain challenges faced by mAb-based tests (see above). Hereby, Nbs exhibit characteristic features such as (i) a nanomolar affinity for their target (39), (ii) a unique epitope recognition spectrum different from conventional antibodies, thereby allowing detection of both free antigens and those bound by host antibodies (40), (iii) high solubility (40), (iv) easy tailorability (multimerization or tagging) for molecular imaging and drug-delivery applications (41-44), and (v) small size that circumvents problems of tissue or blood-brain barrier (BBB) penetrability $(44,45)$. Due to these unique biochemical and biophysical properties, they are considered as promising next-generation therapeutics with great potential in pharmaceutical and industrial applications $(46,47)$. Indeed, Nbs are increasingly exploited in protein structure/function studies and in the development of alternative or new medical diagnostic and therapeutic applications $(48,49)$. Nbs also possess a relatively high thermostability $(50,51)$ and are consequently attractive for the development of immunodiagnostic tests that could be applicable in hot climatic conditions (i.e., sub-Saharan Africa).

In the next sections, we will give an overview of how the $\mathrm{Nb}$ technology can be implemented in the fight against AT both at the level of diagnosis and treatment and finally how acquired knowledge on Nbs in AT might lead to new insights in the function of conventional antibodies in the immune system.

\section{LIFE CYCLE OF AFRICAN TRYPANOSOMES}

In order to point out at which stages Nbs might be applicable to fight AT, it is appropriate to overview briefly their life cycle. African trypanosomes exhibit a digenetic life cycle, alternating between the blood/tissues of the mammalian host and alimentary tract of the tsetse fly vector, whereby they exist as procyclic or trypomastigote forms (52), respectively (see Figure 1). The lifecycle within the mammalian host is initiated upon the bite of a trypanosome-infected tsetse fly when taking a blood meal (see Figure 1). Hereby, metacyclic parasites are inoculated in the host dermis in concert with tsetse saliva components that play a key role in the modulation of the host early immune response and in sculpturing an immune privileged microenvironment for infection initiation (53-55). From the dermal infection site, parasites reach the blood circulation through the lymphatics (55). Subsequently, these metacyclic parasites expressing a heterogeneous metacyclic variable surface glycoprotein (VSG) coat will differentiate into dividing long slender (LS) bloodstream dividing forms (BF), which express a unique VSG coat and are adapted to survive in the glucose-rich and highly oxygenated blood of the mammalian host. Next, these BFs rapidly multiply, giving rise to a first parasitemia peak. At the peak of parasitemia, most likely via a quorum sensing mechanism $(56,57)$, the LS parasites differentiate into non-dividing short stumpy (SS) forms pre-adapted for survival in the tsetse fly vector. Within the tsetse fly vector, these SS forms differentiate within the midgut into procyclic forms (PF) that express a procyclin coat, 


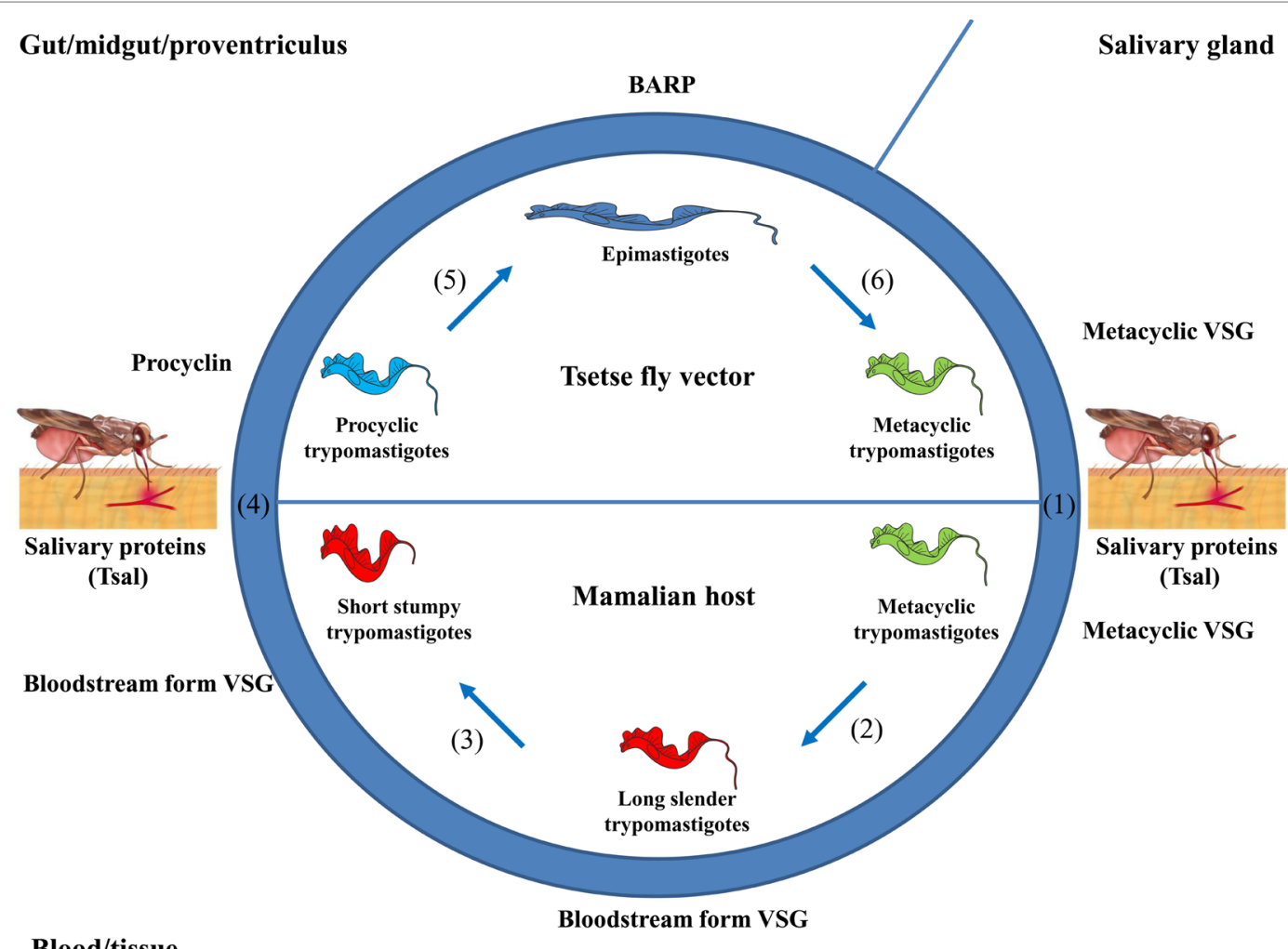

FIGURE 1 | Life cycle of African trypanosomes. (1) Upon the bite of a trypanosome-infected tsetse fly, metacyclic parasites (trypomastigotes) and saliva components (such as Tsal) are inoculated into the mammalian host. (2) The metacyclic parasites [expressing a heterogeneous metacyclic variable surface glycoprotein (VSG)] differentiate into long slender (LS) trypomastigotes (i.e., LS, dividing/proliferating forms, expressing a unique bloodstream form VSG) giving rise to a first peak of parasitemia. (3) At the peak of parasitemia, these LS forms differentiate into non-dividing short stumpy (SS) forms that are pre-adapted to be taken up by the vector. (4) Upon taking a blood meal, these SS forms are ingested and in the midgut these parasites differentiate into procyclic forms (PF), whereby the coat is switched toward procyclin. (5) The PF differentiate into epimastigote forms when migrating to the proventriculus (expressing a bloodstream alanine rich protein coat). (6) Upon migration to the salivary glands, the parasites differentiate into metacyclic forms that are ready to complete their life cycle.

which are adapted to survive in the proline-rich (carbon source) and low-oxygenated environment. Within the tsetse fly, these parasites undergo several differentiation stages in the different parts of the alimentary tract, mouthparts, and salivary glands $(58,59)$. In order to adapt to the growth conditions imposed by the different environments of their hosts, trypanosomes undergo essential morphological and metabolic changes (52), consisting of fine-tuning their energy metabolism, a dedicated iron and nutrient uptake, organelle reorganization, and biochemical and ultrastructural remodeling (60-65). Hence, tools to interfere with the various stages in the parasite life cycle might be an attractive strategy to combat AT.

\section{Nbs AS VERSATILE TOOLS FOR AT}

The control over AT would benefit from more efficient diagnosis and treatment intervention strategies. Hereby, since their serendipitous discovery 30 years ago, Nbs attracted a progressively growing interest from fundamental research on antibody structure and ontogeny to diagnostical and therapeutical applications (66-68). With respect to fundamental research, the $\mathrm{Nb}$ technology was found to provide a novel tool in structural biology, whereby they can be used as crystallization-aid, or as a tool to design novel drugs based on co-crystallization of $\mathrm{Nbs}$ with their cognate antigen $(69,70)$. Although such applications in the field of AT are not yet documented, this will most likely become an emerging field of study in the near future. Moreover, given the tremendous efforts to identify novel targets for AT through proteomic approaches (71), the merging of the $\mathrm{Nb}$ technology with the current technologies might pave the way to develop additional tools/targets to fight AT. In this section, we will give an overview of the applications of the $\mathrm{Nb}$ technology in the field of AT.

\section{Nbs As Tools for Diagnosis}

To date, several obstacles hamper an efficient and reliable diagnosis of AT, whereby (i) inefficient antibody-based detection due to interferences caused by the host's antibody response (i.e., antibodies remaining in circulation for long periods of time) impairs discrimination between active and cured infections and (ii) antigen-based trypanosome detection methods that might allow circumventing the problems encountered in the antibodybased detection system are not yet available. In this context, Nbs are emerging as promising tools to overcome the limitations of 
antibody-based diagnosis and to improve antigen-based detection of African trypanosomes (see Figure 2 and Table 1). For instance, though the binding interference caused by the host's antibody response upon infection might hamper sensitive detection, this response might also be exploited using the $\mathrm{Nb}$ technology. Indeed, Caljon et al. (72) showed that following immunization of an alpaca with the sialome of the savannah tsetse fly vector (Glossina morsitans morsitans), Nbs could be generated against an abundant highly immunogenic tsetse salivary gland (Tsal) endonuclease protein and could subsequently be used to monitor tsetse fly bite exposure (73). Monitoring this bite exposure level in a target host population is important as the probability of a trypanosome transmission event to a new host is directly linked to the exposure level of the host to tsetse bites in that area (=risk factor). Indeed, only a very limited number of flies in a natural tsetse population carries the final infective parasite stage, so the more frequent a host is bitten by tsetse the higher the risk is that it will trap a trypanosome infection through the bite of a rarely occurring infected fly in that area. The assay principle relies on the detection of specific

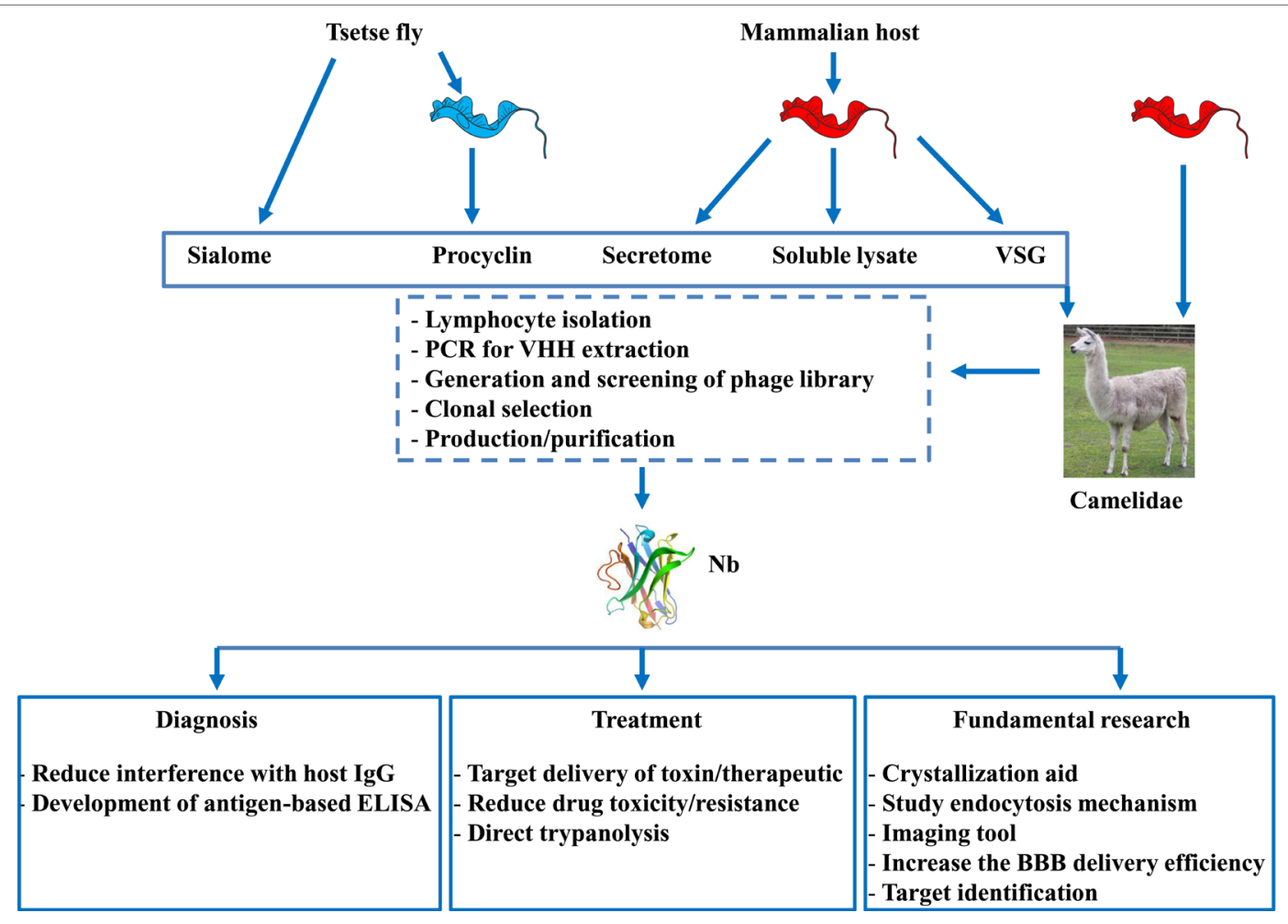

FIGURE 2 | Overview of strategies used to generate nanobodies (Nbs) and their applications. Nbs can be obtained from llama's that are either immunized with factors derived from (i) tsetse flies (i.e., sialome or procyclin coat isolated form procyclic forms) or (ii) purified blood stream parasites originally grown in the mammalian host [i.e., secretome, soluble lysate, or variable surface glycoprotein (VSG)] or (iii) from infected (naturally or experimentally) with trypanosomes. After immunization, lymphocytes are isolated from the blood and via the PCR, phage display, and different selection procedures, individual Nbs can be obtained and purified. These Nbs can find application in diagnosis, therapy, or be used for fundamental research aiming at developing novel strategies to fight African trypanosomiasis.

TABLE 1 | Overview of the different targets against which nanobodies (Nbs) have been generated.

\begin{tabular}{|c|c|c|c|c|c|c|c|}
\hline Target & Vector & PF & BF & Specificity & Diagnosis & Treatment & Reference \\
\hline Tsal & + & - & - & Saliva & + & - & $(72)$ \\
\hline Procyclin & - & + & - & Tb & $?$ & $?$ & - \\
\hline Aldolase & - & - & + & Tc & + & $?$ & (78) \\
\hline Paraflagellar rod protein & - & + & + & Te, Tb, Tc, Tv & + & $?$ & $(77)$ \\
\hline Conserved variable surface glycoprotein (VSG) epitope & - & - & + & $\mathbf{T b},(T c ?)$ & + & + & (81) \\
\hline Variable VSG epitope & - & - & + & $\mathbf{T b},(\mathrm{Tc} ?)$ & + & + & (98) \\
\hline Transferrin receptor & - & $?$ & + & Tb, Tc, Te, Tv & $?$ & $?$ & - \\
\hline
\end{tabular}

In addition, the Nb specificity and applicability (diagnosis/treatment) is mentioned.

PF, procyclic forms; BP, bloodstream form; Th, Trypanosoma brucei; Tc, Trypanosoma congolense; Te, Trypanosoma evansi; TV, Trypanosoma vivax.

Trypanosome species in bold refers to the species against which the target was originally generated.

"?" stands for not tested or unknown. 
anti-Tsall antibodies in an assay that measures the competitive binding onto the immunogenic Tsallprotein of diagnostic Nbs (Tsal1Nb-5 and -11) and host antibodies that are typically induced by bite exposure. This Nb-based competition assay allows specific detection of exposure to a range of important tsetse fly species in the context of sero-epidemiological surveys based on salivary proteins. This could not only allow monitoring/ estimating the intensity of the host exposure to tsetse fly bites but also reveal the efficacy of applied and/or ongoing tsetse fly control activities. This approach might be further extended by generating anti-proteome and/or anti-infectome $\mathrm{Nb}$ libraries in order to identify diagnostic Nbs (74-76). Indeed, the work by Obishakin et al. (77) showed that upon immunization of a llama with $T$. evansi lysate, Nbs against the paraflagellar rod (PFR) protein of trypanosomes could be generated and used in a solid phase antigen-ELISA to detect this protein in different T. evansi strains. Although the assay was not sensitive enough to detect T. congolense and T. vivax lysates in ELISA, one of the anti-PFR Nbs (Nb392) was found to cross-react with multiple parasite species such as T. brucei, T. congolense, and T. vivax as well as PF. Detection was achieved using fixed and permeabilized parasites and via flow cytometry and immunofluorescence microscopy, inferring that this $\mathrm{Nb}$ could be used to develop a broad spectrum diagnostic reagent. Moreover, this $\mathrm{Nb}$ could also be exploited as a PFR marker and/or as a useful research tool to isolate PFR proteins. More recently, Odongo et al. (78) identified following immunization of a llama with the soluble proteome of bloodstream form (BF) T. congolense a $\mathrm{Nb}$ (Nb474) recognizing glycosomal aldolase (TcoALD) that could be used in a Nb-based sandwich ELISA to specifically detect active T. congolense infections in experimentally and naturally infected cattle. In experimental T. congolense infection models, parasitemia and detected antigenemia followed the same trend and the assay was suggested to be suitable as a test of cure. Although no formal detection limit was determined, the Nb474-based test was able to detect $T$. congolense infections in two field collected cattle blood samples that underwent the traditional parasitological diagnosis using the buffy coat technique followed by 18S-PCRRFLP-based parasite species identification. Furthermore, it was suggested that the robustness of this $\mathrm{Nb} 474$-ELISA to specifically monitor T. congolense infections in the field might be improved once the structural and biophysical determinants of the specific Nb474-TcoALD interaction can be determined. Of note, also in other parasitic diseases such as malaria, aldolase was reported as a proficient biomarker for the detection of Plasmodium vivax (79). In addition, in regions of sub-Saharan Africa where animals are infected with human and animal infective trypanosomes, this selective test for $T$. congolense using aldolase as a biomarker would allow discriminating between the two parasite groups, hence enabling assessment of the potential risk for human infection (80).

Besides recognizing low abundant proteins, $\mathrm{Nbs}$ have also been generated against the highly abundant VSG coat of the $T$. congolense parasite, yet due to the system of antigenic variation their diagnostic value is rather limited (unpublished data). However, the work by Stijlemans et al. (81), using the T. brucei model parasites, showed that the reduced size of a $\mathrm{Nb}$ allows to target conserved, less-immunogenic, cryptic VSG epitopes, that are inaccessible to conventional antibodies. Hereby, the fluorescently labeled anti-VSG Nb-33 was found to be very proficient to detect different isoforms of the T. brucei family and to specifically stain trypanosomes in infected blood. This suggests that even Nbs directed against specific conserved regions of the VSG molecule can be used as diagnostic tools.

Collectively, these data suggest that a Nb-based strategy could be a unique approach for diagnosis development and might bring us a step closer toward obtaining an antigen-detection test that can be used for rapid and reliable detection of vector exposure as well as the presence of pathogen infections in reservoir hosts (see Figure 2 and Table 1). In addition, Nbs could also be used for target discovery given that following immunizations with complex protein mixtures and via different purification techniques, their cognate antigens with diagnostic potential can be identified.

\section{Nbs As Therapeutic Devices Nbs As Tools for Drug/Toxin Delivery}

Although the currently used chemotherapeutics are proficient in killing trypanosomes, their in vivo application suffers from systemic drug toxicity and occurrence of drug resistance (82). Therefore, delivering the chemotherapeutic (or toxin) directly to the parasite could be a more efficient way for treating AT. The possibility of using Nbs as targeting entity was investigated using the Nb-33 as model Nb (Figure 2; Table 1). With respect to using $\mathrm{Nb}-33$ as a toxin-delivery system to African trypanosomes, apolipoprotein L-1 (ApoL-1) was selected as a trypanolytic component. ApoL-1 is a component of normal human serum (NHS) that exerts a direct trypanolytic effect on all AAT species, except resistant forms such as T. brucei rhodesiense (83). Indeed, T. $b$. rhodesiense expresses the apoL-I-neutralizing serum resistance-associated (SRA) protein, endowing this parasite with the ability to infect humans and cause HAT $(83,84)$. Hence, Nb-33, recognizing a conserved/cryptic region within the VSG coat, was coupled to a truncated form of Apo-L1 (i.e., Tr-apoL-1), which is engineered by deleting the SRA-interacting domain. This engineered immunotoxin was shown to function curatively and to alleviate effects on acute and chronic infections in mice infected with both NHS-resistant and sensitive parasites $(85,86)$. The Nb-33 was also used as a delivery system for therapeutics using T. b. gambiense parasites as a model. Hereby, nanoparticles loaded with pentamidine [i.e., drug used for treating the early disease stage, before central nervous system involvement (87), as the second-line option to suramin] were coupled to $\mathrm{Nb}$-33. This targeted drug-bullet allowed decreasing the halfinhibitory concentration (IC50) 7-fold compared to free drug in vitro and cured all mice at a 10 -fold lower dose than the minimal full curative dose of free pentamidine (88-90). Moreover, recently an improved version of this nanocarrier allowed reducing the curative dose 100-fold and circumvented drug resistance that is due to mutations in aquaglyceroporin 2 (i.e., the surface channel protein that mediates pentamidine uptake in T. brucei) $(29,91,92)$. Overall, targeting the trypanosome surface using $\mathrm{Nb}$-coated drug-loaded nanoparticles can be an elegant way to deliver drugs via endocytosis and bypass the usual drug delivery 
route altogether. Recently, using the $\mathrm{Nb}-33$, it was shown that Nbs are able to pass the BBB during the late stage of T. bruce $i$ infection using murine and rat models, which suggests they might be valuable tools to target toxins even at the levels of the BBB. Yet, they were incapable of accumulating in the brain at therapeutically relevant concentrations (93), which is most likely due to the systemic pharmacokinetics of monovalent Nbs $(42,94)$. Hence, efforts should be undertaken to tailor these Nbs via for instance CDR grafting to yield improved brain penetrating properties without losing their beneficial size $(95,96)$. In addition, to quantitatively study the penetration of Nbs into the CNS in vivo, intracerebral microdialysis represents a powerful and sensitive technique. Given that much effort is put into developing new drugs against African trypanosomes, the $\mathrm{Nb}$-based drug/toxin-delivery approach might allow increasing their efficacy, even against drug resistant parasites, and be applicable for many other diseases (97).

\section{Nbs As Direct Trypanolytic Entities by Blocking Endocytosis}

By serendipity, besides a drug-targeting potential, Nbs were found to exert direct trypanolytic activities. Indeed, it was shown that some Nbs specific for the variable part of VSG of T. b. brucei parasites were able to induce parasite lysis in vitro. The lytic process consists of a rapid immobilization of the parasites, followed by massive enlargement of the flagellar pocket and a major blockage of endocytosis (98). Given that endocytosis is essential for trypanosome survival, playing a key role in nutrient uptake and in regulating intracellular ATP-levels as well as in maintaining the mitochondrial membrane potential, it is a prime candidate target for therapeutic interventions (99). Moreover, the endocytosis is confined to the flagellar pocket, which can be considered as the gateway to and from the cell surface that regulates the host-parasite interface as well as significantly contributes toward interactions with therapeutics. Hence, this might be the trypanosomal Achilles' heel and offer perspectives for directed drug delivery focusing on proteins essential in endocytosis (100). Also, targeting specific receptors essential for nutrient uptake could be considered as therapeutic targets. For instance, given that iron is essential for the survival of both the trypanosome and the mammalian host and that their receptor for iron/transferrin uptake differs (i.e., a heterodimer and homodimer, respectively) (101), specific targeting of the parasite transferrin receptor using Nbs might be an opportunity to selectively deprive trypanosomes from this essential nutrient or alternatively be used as drug delivery or diagnostic tool. Also, the fact that low-molecular weight VSG-specific trypanolytic Nbs can impede endocytosis suggests that Nbs can be used as tools to further unravel the fascinating endocytosis mechanism used by trypanosomes. This in turn may offer new opportunities for developing novel trypanosomiasis therapeutics aimed at affecting endocytosis.

One aspect that could compromise the therapeutic applications of $\mathrm{Nbs}$, in for instance HAT patients, is the potential immunogenicity of $\mathrm{Nbs}$, especially in treatments that require repeated injections. Currently, the immunogenicity of $\mathrm{Nb}$-based therapeutic applications is controversial. For instance, a clinical trial study conducted by GSK revealed the occurrence of anti-TNFR1 $\mathrm{Nb}$ autoantibodies and in another study with a tetravalent anti-DR5 receptor $\mathrm{Nb}$ hepatotoxicity in patients with such pre-existing antibodies has been described $(102,103)$. By contrast, no anti-HER2 $\mathrm{Nb}$ autoantibodies could not be detected in patients who received a non-humanized Nb (104), nor in patients receiving a $\mathrm{Nb}$ against von Willebrand factor (105). Also in the murine model, so far, multiple injections of Nbs in different disease settings did not result in immunogenicity, neither at the level of specific antibodies against Nbs nor at the level of cell proliferation and cytokine levels $(68,106-108)$. Hence, it seems that the occurrence of immunogenicity might depend on the target and disease situation (46). Yet, to reduce/minimize the risk of an immune response within the mammalian host, there are strategies currently implemented, such as humanization of the Nbs, whereby the camelid-specific amino acid sequences are mutated to their human heavy chain variable domain equivalent. In this context, a universal humanized $\mathrm{Nb}$ scaffold has been generated that allows grafting the antigen-binding loops from other $\mathrm{Nbs}$, thereby transferring the antigen specificity and affinity (109).

\section{Paratransgenesis As Tool to Deliver Nbs within the Tsetse Fly Vector}

The applications of Nbs against AT may be not restricted to the $\mathrm{BF}$ of the parasites within the mammalian host, but could be applied/extrapolated to the vector. In this context, the possibility to exploit the tsetse fly bacterial symbiont Sodalis glossinidius as a paratransgenic platform organism for the expression and delivery of trypanosome-interfering proteins (i.e., Nbs) within the tsetse fly vector was evaluated. To this end, both the non-lytic $\mathrm{Nb}-33$ and the trypanolytic Nbs were shown to be successfully expressed without affecting S. glossinidius fitness/viability (110). Moreover, using the trypanolytic $\mathrm{Nb}$ as proof of concept, recombinant $S$. glossinidius could settle in different tsetse fly tissues at high densities. Furthermore, significant levels of functional anti-trypanosome Nbs were released in several tissues including the midgut where important developmental stages of the parasite reside (111). Here, the level of $\mathrm{Nb}$ expression was estimated to be in the low nanogram ( $<10 \mathrm{ng})$, which was calculated to be sufficient to lyse the expected low number of transforming blood stream trypanosomes (around $10^{3}$ parasites) in the tsetse midgut during the early developmental period after ingestion by the fly (111). Accordingly, this paratransgenic approach using Sodalis to deliver Nbs that target the parasite or the trypanosome-tsetse fly cross talk could open new avenues to unravel the molecular determinants of this specific parasite-vector interplay and to ultimately render tsetse flies trypanosome resistant [reviewed by Caljon et al. (112)]. Given that the trypanosome is not exposed to an adaptive immune system in the tsetse vector, this parasite stage is not undergoing antigenic variation with the major surface antigen being encoded by a limited set of procyclin genes. In this context, the potential of Nbs delivered using the Sodalis endosymbiont targeting the major developmental stages in the tsetse fly, such as the procyclic trypanosomes that need to overcome the midgut barrier in order to achieve colonization of the tsetse fly vector, is currently being investigated. Stable integration of 
$\mathrm{Nb}$ expression cassettes in the Sodalis genome (e.g., by using recently established procedures) and efficient vertical transfer of the transgenic Sodalis have been achieved (113). Important issues, such as the identification of highly potent infectionblocking Nbs and the increased proteolytic stability, are still to be addressed (114). The latter feature will be highly beneficial to maintain potent effector levels in the strong proteolytic digestive environment of the insect midgut. Yet, such strategies could potentially culminate in a drug-targeting strategy to eliminate trypanosomes within the tsetse fly vector. An important achievement in the context of the Sodalis-based paratransgenesis is the efficient transfer of genetically modified Sodalis from the mother tsetse fly to its offspring through intrauterine nourishment (113). This implies that a large-scale tsetse fly colony can be established of flies harboring a $\mathrm{Nb}$-expressing Sodalis. The paratransgenic trypanosome-resistant male flies from these colonies can then be released (after sterilization through irradiation) at a massive scale in the context of the Sterile Insect Technique (SIT). SIT was already successfully used to eradicate the tsetse fly in Zanzibar and is currently an important pillar in the tsetse fly control campaigns in Ethiopia and Senegal (http://www.fao. org/in-action/senegal-celebrates-first-victory-against-tsetse-flyeradication/en/).

\section{LYTIC NbS: RELEVANCE IN VIVO?}

The observation that the antigen-binding domain (i.e., $\mathrm{Nb}$ ) on itself, in the absence of the Fc part can exert a significant Fc-independent killing of African trypanosomes in vitro and in vivo is remarkable (98). Moreover, it was found that both the size and affinity were of crucial importance for this trypanolytic activity $(98,115)$. Indeed, whereas polyclonal antibodies (including heavy-chain antibodies) specific for the VSG of African trypanosomes are completely harmless to trypanosomes in the absence of complement or any other bystander effector $(116,117)$, polyclonal Fabs or Nbs derived from the serum antibody pools and monoclonal/polyclonal Fabs or Nbs that are deprived of all effector functions (i.e., Fc) could exhibit an intrinsic trypanolytic activity in vitro (98). It is surprising that removal of the Fc part from antibodies unveils a novel but deadly situation, because trypanosomes and other extracellular pathogens mostly coped during evolution with intact immunoglobulins and thus developed multiple ways to avoid the destructive action of such large molecules $(118,119)$. In case of African trypanosomes such escape mechanisms include (i) antigenic variation of the VSGs, (ii) dense packing of VSG molecules on the parasite's coat prohibiting the recognition of conserved and/or physiologically important epitopes by intact antibodies, (iii) clearing of VSGbound antibodies by endocytosis of the VSG-antibody complex [reviewed in Ref. (120-123)]. In contrast to intact Abs, the small-sized Fabs or Nbs may penetrate the dense VSG coat and trigger new processes or avoid removal of VSG-antibody complexes, which is dictated by the bivalency of Abs (possibly due to cross-linking of the VSGs) and/or antibody size, e.g., whereby the presence of the Fc part leads to steric occlusion $(123,124)$.

The concept that the Fc part within an antibody is masking the intrinsic destructive capacity of the antigen-binding fragment is intriguing. Consequently, other polyclonal or mAbs may share similar features and harbor hidden activities that remain occluded within intact Abs and might manifest themselves upon generation of monovalent Fabs or Nbs (see Figure 3). Evidence for a possible intrinsic anti-pathogen activity of in vivo generated Fabs or Nbs within the bona fide antibody independent of the Fc part is difficult to provide as there is so far no simple assay to demonstrate such an event. Nevertheless, such mechanisms might exist as Nbs with competitive enzyme-inhibiting activity or Fabs with catalytic activity (termed Abzymes) have been identified (117-120). Under certain conditions, antibodies were documented to exert bactericidal activities in the absence of complement or phagocytes (125). For instance, antibodies catalyze the generation of hydrogen peroxide $\left(\mathrm{H}_{2} \mathrm{O}_{2}\right)$ from singlet molecular oxygen and water, thereby producing an additional molecular species with a chemical signature similar to that of ozone (126). Interestingly, this singlet molecular oxygen is only present when the host is under assault, thereby making it an "event-triggered" substrate and consequently suggests that the additional function of an antibody might only be apparent under "inflammatory" conditions (127). In addition, it was shown that high $\mathrm{H}_{2} \mathrm{O}_{2}$ in concert with transition metal ions $\left(\mathrm{FeCl}_{2}\right)$ (i.e., factors that are typically produced/released via apoptotic neutrophils during inflammation) can generate hydroxyl radicals ( $v i a$ a Fenton-like reaction) that induce hinge fragmentation of IgG1 mAb [(128) consisting of (i) a Fab domain and the upper hinge of one of the Fc domains and (ii) another Fab domain linked to the Fc domain (see proposed model in Figure 3)]. This indicates that under certain in vivo inflammatory conditions hidden biological activities could become unmasked from bona fide antibodies. To the best of our knowledge, the observation that an antibodyderived fragment on itself can exert a biological function is a new conceptual insight which might broaden the potentiality of $\mathrm{Ab}$ applications in different fields.

\section{CONCLUSION AND FUTURE PERSPECTIVES}

Over the years, Nbs have been found to be valuable tools in the field of AT both at the level of diagnosis and treatment. They were shown to have potential to circumvent problems encountered with antibody-based detection systems and in addition allow the development of antigen-based approaches that were so far lacking (32). With the era of proteomics (71), allowing additional biomarkers to be discovered, the application of a Nb-based immunoproteomic approach might allow developing more efficient tools to improve trypanosomiasis control (diagnosis/treatment) in the near future. With respect to treatment against $\mathrm{AT}$, it seems that $\mathrm{Nbs}$ are a very proficient tool to deliver drugs/toxins to parasites, thereby reducing the side effects due to drug toxicity and possibly the probability to develop drug resistance. Their small size, low immunogenicity, and tailorability furthermore favor their application in AT with respect to $\mathrm{BBB}$ drug delivery, routine/systemic administration, and generation of half-life extended formats. Also for research purposes, their advantages are increasingly appreciated and 


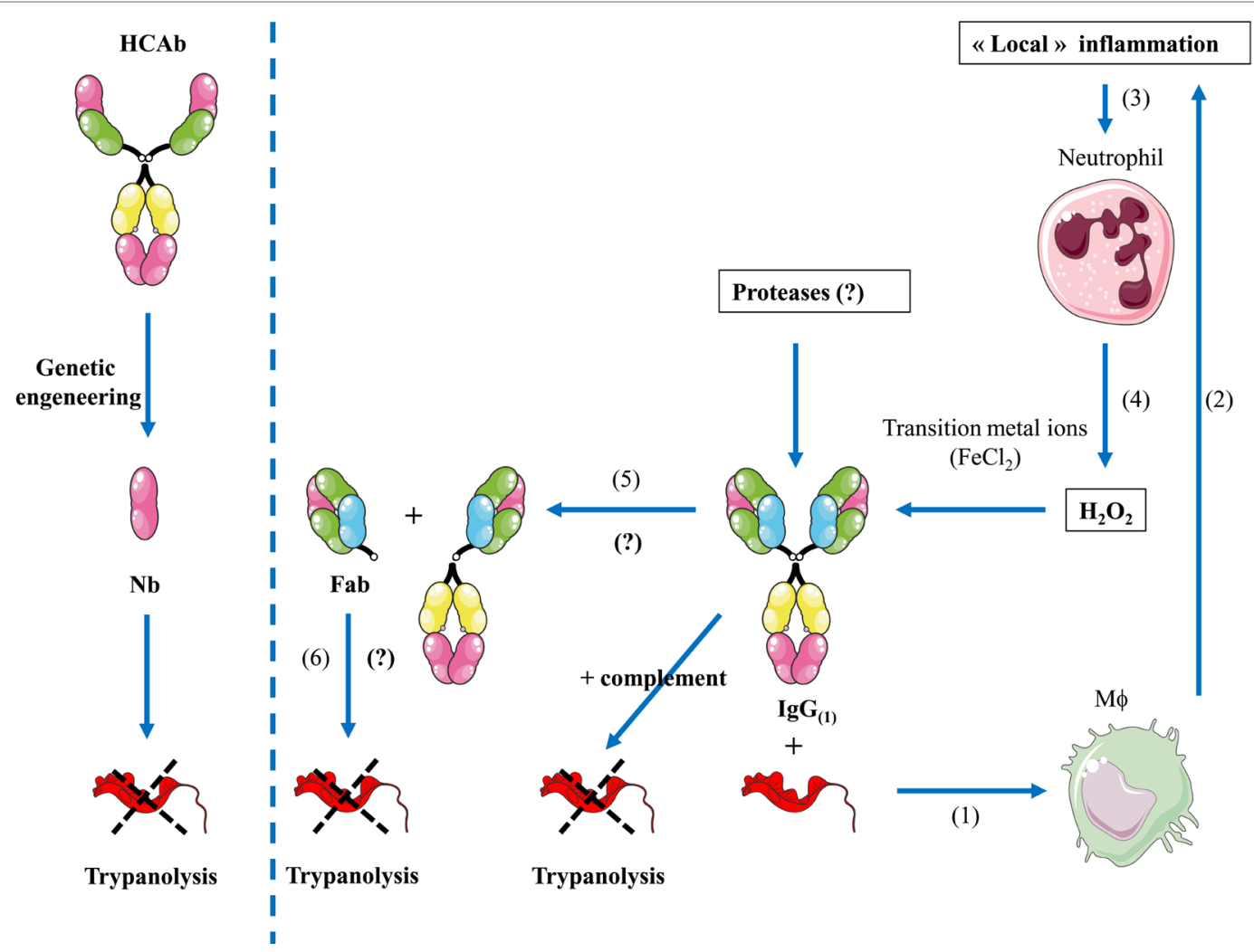

FIGURE 3 | Proposed model of "hidden" functions of antibodies during inflammation. (Left panel) Through genetic engineering, camelid-derived heavy-chain antibodies (HCAbs) can be fragmented to the size of a nanobody that might exert a direct effect on pathogens (i.e., trypanosomes). (Right panel) (1) During infection (i.e., trypanosome infection), parasite-derived factors in concert with host-derived factors trigger macrophage (Mф) activation. (2) Hereby, elicited antibodies opsonize parasites and in concert with complement trigger parasite destruction, further leading to release of macrophage activating components and inflammatory responses. (3) The local inflammation may lead to recruitment, activation, and apoptosis of neutrophils. (4) Release of $\mathrm{H}_{2} \mathrm{O}_{2}$ as well as transitional metal ions and proteases by neutrophils/activated macrophages can fragment intact $\operatorname{lgG}$ (1). (5) Next, this will induce hinge fragmentation of IgG1 giving rise to a fragmented antibody into moieties including the Fab domain. (6) This Fab domain might exert a direct lytic effect on trypanosomes.

they will most likely become a useful tool with respect to crystallization and imaging. Finally, the concept that a $\mathrm{Nb}$ or a Fab fragment derived from an intact IgG might exert a biological function by itself in the absence of the Fc-bystander warrants further investigation. Moreover, this suggests that intact antibodies harbor hidden functions that only become apparent upon fragmentation into a Fab, a process that might occur under certain conditions, and this might have a broad range of implications and applications in other diseases.

\section{AUTHOR CONTRIBUTIONS}

BS, PB, GC, JA, JG, and SM collectively wrote the manuscript.

\section{REFERENCES}

1. Yaro M, Munyard KA, Stear MJ, Groth DM. Combatting African animal trypanosomiasis (AAT) in livestock: the potential role of trypanotolerance. Vet Parasitol (2016) 225:43-52. doi:10.1016/j.vetpar.2016.05.003

2. Simarro PP, Cecchi G, Franco JR, Paone M, Diarra A, Ruiz-Postigo JA, et al. Estimating and mapping the population at risk of sleeping sickness. PLoS Negl Trop Dis (2012) 6:e1859. doi:10.1371/journal.pntd.0001859

\section{FUNDING}

We acknowledge the financial support of the Interuniversity Attraction Pole Program (PAI-IAP N. P7/41, http://www.belspo. be/belspo/iap/index_en.stm) and grants from the FWO (FWO G015016N and G.0.028.10.N.10) and the Bill and Melinda Gates Foundation grant $641 \mathrm{~K} 760$. BS is a research fellow supported by the Strategic Research Program (SRP3, VUB): targeting inflammation linked to infectious diseases and cancer (Nanobodies for Health). GC is funded by a research fund of the University of Antwerp (TT-ZAPBOF 33049). The funders had no role in study design, data collection and analysis, decision to publish, or preparation of the manuscript.

3. Franco JR, Simarro PP, Diarra A, Jannin JG. Epidemiology of human African trypanosomiasis. Clin Epidemiol (2014) 6:257-75. doi:10.2147/ CLEP.S39728

4. World Health Organization. Control and surveillance of human African trypanosomiasis. World Health Organ Tech Rep Ser (2013) (984):1-237.

5. Kennedy PG. Clinical features, diagnosis, and treatment of human African trypanosomiasis (sleeping sickness). Lancet Neurol (2013) 12:186-94. doi:10.1016/S1474-4422(12)70296-X 
6. Welburn SC, Molyneux DH, Maudlin I. Beyond tsetse - implications for research and control of human African trypanosomiasis epidemics. Trends Parasitol (2016) 32:230-41. doi:10.1016/j.pt.2015.11.008

7. MacLean LM, Odiit M, Chisi JE, Kennedy PG, Sternberg JM. Focus-specific clinical profiles in human African trypanosomiasis caused by Trypanosoma brucei rhodesiense. PLoS Negl Trop Dis (2010) 4:e906. doi:10.1371/journal. pntd.0000906

8. WHO. Control and surveillance of human African trypanosomiasis. World Health Organ Tech Rep Ser (2013):1-237. Available from: http://www.ncbi. nlm.nih.gov/pubmed/24552089

9. MacLean L, Reiber H, Kennedy PG, Sternberg JM. Stage progression and neurological symptoms in Trypanosoma brucei rhodesiense sleeping sickness: role of the CNS inflammatory response. PLoS Negl Trop Dis (2012) 6:e1857. doi:10.1371/journal.pntd.0001857

10. Simarro PP, Diarra A, Ruiz Postigo JA, Franco JR, Jannin JG. The human African trypanosomiasis control and surveillance programme of the World Health Organization 2000-2009: the way forward. PLoS Negl Trop Dis (2011) 5:e1007. doi:10.1371/journal.pntd.0001007

11. World Health Organization. Trypanosomiasis, Human African (Sleeping Sickness). (Vol. 259). World Health Organization (2013). Fact Sheet. Available from: http://www.who.int/mediacentre/factsheets/ss259/en/

12. Lejon V, Bentivoglio M, Franco JR. Human African trypanosomiasis. Handb Clin Neurol (2013) 114:169-81. doi:10.1016/B978-0-444-53490-3.00011-X

13. Ruiz-Postigo JA, Franco JR, Lado M, Simarro PP. Human African trypanosomiasis in South Sudan: how can we prevent a new epidemic? PLoS Negl Trop Dis (2012) 6:e1541. doi:10.1371/journal.pntd.0001541

14. Hasker E, Mpanya A, Makabuza J, Mbo F, Lumbala C, Kumpel J, et al. Treatment outcomes for human African trypanosomiasis in the Democratic Republic of the Congo: analysis of routine program data from the world's largest sleeping sickness control program. Trop Med Int Heal (2012) 17: 1127-32. doi:10.1111/j.1365-3156.2012.03042.x

15. Claes F, Büscher P, Touratier L, Goddeeris BM. Trypanosoma equiperdum: master of disguise or historical mistake? Trends Parasitol (2005) 21:316-21. doi:10.1016/j.pt.2005.05.010

16. Desquesnes M, Dargantes A, Lai DH, Lun ZR, Holzmuller P, Jittapalapong S. Trypanosoma evansi and surra: a review and perspectives on transmission, epidemiology and control, impact, and zoonotic aspects. Biomed Res Int (2013) 2013:321237. doi:10.1155/2013/321237

17. Brun R, Hecker H, Lun ZR. Trypanosoma evansi and T. equiperdum: distribution, biology, treatment and phylogenetic relationship (a review). Vet Parasitol (1998) 79:95-107. doi:10.1016/S0304-4017(98)00146-0

18. Naessens J. Bovine trypanotolerance: a natural ability to prevent severe anaemia and haemophagocytic syndrome? Int J Parasitol (2006) 36:521-8. doi:10.1016/j.ijpara.2006.02.012

19. Giordani F, Morrison LJ, Rowan TG, De Koning HP, Barrett MP. The animal trypanosomiases and their chemotherapy: a review. Parasitology (2016) 143(14):1862-89. doi:10.1017/S0031182016001268

20. Swallow B. Impacts of Trypanosomiasis on African Agriculture. Nairobi, Kenya: Int Livest Res Institute (1999). p. 1-46. Available from: http://www. cabdirect.org/abstracts/20003010139.html

21. Gilbert M, Jenner C, Pender J, Rogers D, Slingenbergh J, Wint W. The programme against African trypanosomiasis information system (PAATIS). In: The African Trypanosomiasis. Vol 1 World Class Parasites. p. 11-24. Available from: https://link.springer.com/chapter/ 10.1007/0-306-46894-8_2?no-access=true

22. Baker N, de Koning HP, Maser P, Horn D. Drug resistance in African trypanosomiasis: the melarsoprol and pentamidine story. Trends Parasitol (2013) 29:110-8. doi:10.1016/j.pt.2012.12.005

23. Delespaux V, de Koning HP. Drugs and drug resistance in African trypanosomiasis. Drug Resist Updat (2007) 10:30-50. doi:10.1016/j.drup.2007.02.004

24. Bouyer J, Bouyer F, Donadeu M, Rowan T, Napier G. Community- and farmerbased management of animal African trypanosomosis in cattle. Trends Parasitol (2013) 29:519-22. doi:10.1016/j.pt.2013.08.003

25. Wenzler T, Schumann Burkard G, Schmidt RS, Mäser P, Bergner A, Roditi I, et al. A new approach to chemotherapy: drug-induced differentiation kills African trypanosomes. Sci Rep (2016) 6:22451. doi:10.1038/srep22451

26. Naula C, Burchmore R. A plethora of targets, a paucity of drugs: progress towards the development of novel chemotherapies for human
African trypanosomiasis. Expert Rev Anti Infect Ther (2003) 1:157-65. doi:10.1586/14787210.1.1.157

27. Haanstra JR, Gerding A, Dolga AM, Sorgdrager FJ, Buist-homan M, Toit F, et al. Targeting pathogen metabolism without collateral damage to the host. Sci Rep (2017) 7:40406. doi:10.1038/srep40406

28. Barrett MP, Vincent IM, Burchmore RJ, Kazibwe AJ, Matovu E. Drug resistance in human African trypanosomiasis. Futur Microbiol (2011) 6:1037-47. doi:10.2217/fmb.11.88

29. Unciti-Broceta JD, Arias JL, Maceira J, Soriano M, Ortiz-González M, Hernández-Quero J, et al. Specific cell targeting therapy bypasses drug resistance mechanisms in African trypanosomiasis. PLoS Pathog (2015) 11:e1004942. doi:10.1371/journal.ppat.1004942

30. Kroubi M, Karembe H, Betbeder D. Drug delivery systems in the treatment of African trypanosomiasis infections. Expert Opin Drug Deliv (2011) 8:735-47. doi:10.1517/17425247.2011.574122

31. Kennedy PG. Human African trypanosomiasis-neurological aspects. J Neurol (2006) 253:411-6. doi:10.1007/s00415-006-0093-3

32. Bonnet J, Boudot C, Courtioux B. Overview of the diagnostic methods used in the field for human African trypanosomiasis: what could change in the next years? Biomed Res Int (2015) 2015:583262. doi:10.1155/2015/ 583262

33. Jamonneau V, Camara O, Ilboudo H, Peylhard M, Koffi M, Sakande H, et al. Accuracy of individual rapid tests for serodiagnosis of gambiense sleeping sickness in West Africa. PLoS Negl Trop Dis (2015) 9(2):e0003480. doi:10.1371/journal.pntd.0003480

34. Rebeski DE, Winger EM, Rogovic B, Robinson MM, Crowther JR, Dwinger RH. Improved methods for the diagnosis of African trypanosomosis. Mem Inst Oswaldo Cruz (1999) 94:249-53. doi:10.1590/S007402761999000200024

35. Moti Y, Fikru R, Buscher P, Van Den Abbeele J, Duchateau L, Delespaux V. Detection of African animal trypanosomes: the haematocrit centrifugation technique compared to PCR with samples stored on filter paper or in DNA protecting buffer. Vet Parasitol (2014) 203:253-8. doi:10.1016/j.vetpar.2014.04.014

36. Lambert PH, Berney M, Kazyumba G. Immune complexes in serum and in cerebrospinal fluid in African trypanosomiasis. J Clin Invest (1981) 67:77-85. doi:10.1172/JCI110035

37. Hamers-Casterman C, Atarhouch T, Muyldermans S, Robinson G, Hamers C, Songa EB, et al. Naturally occurring antibodies devoid of light chains. Nature (1993) 363:446-8. doi:10.1038/363446a0

38. Dmitriev OY, Lutsenko S, Muyldermans S. Nanobodies as probes for protein dynamics in vitro and in cells. J Biol Chem (2016) 291:3767-75. doi:10.1074/ jbcR115.679811

39. Skottrup PD, Leonard P, Kaczmarek JZ, Veillard F, Enghild JJ, O'Kennedy R, et al. Diagnostic evaluation of a nanobody with picomolar affinity toward the protease RgpB from Porphyromonas gingivalis. Anal Biochem (2011) 415:158-67. doi:10.1016/j.ab.2011.04.015

40. De Genst E, Silence K, Decanniere K, Conrath K, Loris R, Kinne J, et al. Molecular basis for the preferential cleft recognition by dromedary heavychain antibodies. Proc Natl Acad Sci U S A (2006) 103:4586-91. doi:10.1073/ pnas. 0505379103

41. Oliveira S, Heukers R, Sornkom J, Kok RJ, van Bergen en Henegouwen PMP. Targeting tumors with nanobodies for cancer imaging and therapy. J Control Release (2013) 172:607-17. doi:10.1016/j.jconrel.2013.08.298

42. De Groeve K, Deschacht N, De Koninck C, Caveliers V, Lahoutte T, Devoogdt N, et al. Nanobodies as tools for in vivo imaging of specific immune cell types. J Nucl Med (2010) 51:782-9. doi:10.2967/jnumed.109. 070078

43. De Vos J, Devoogdt N, Lahoutte T, Muyldermans S. Camelid single-domain antibody-fragment engineering for (pre)clinical in vivo molecular imaging applications: adjusting the bullet to its target. Expert Opin Biol Ther (2013) 13:1149-60. doi:10.1517/14712598.2013.800478

44. Movahedi K, Schoonooghe S, Laoui D, Houbracken I, Waelput W, Breckpot K, et al. Nanobody-based targeting of the macrophage mannose receptor for effective in vivo imaging of tumor-associated macrophages. Cancer Res (2012) 72:4165-77. doi:10.1158/0008-5472.CAN-11-2994

45. Zheng F, Devoogdt N, Sparkes A, Morias Y, Abels C, Stijlemans B, et al. Monitoring liver macrophages using nanobodies targeting Vsig4: 
concanavalin A induced acute hepatitis as paradigm. Immunobiology (2015) 220:200-9. doi:10.1016/j.imbio.2014.09.018

46. Muyldermans S, Smider VV. Distinct antibody species: structural differences creating therapeutic opportunities. Curr Opin Immunol (2016) 40:7-13. doi:10.1016/j.coi.2016.02.003

47. Wesolowski J, Alzogaray V, Reyelt J, Unger M, Juarez K, Urrutia M, et al. Single domain antibodies: promising experimental and therapeutic tools in infection and immunity. Med Microbiol Immunol (2009) 198:157-74. doi:10.1007/s00430-009-0116-7

48. Hassanzadeh-Ghassabeh G, Devoogdt N, De Pauw P, Vincke C, Muyldermans S. Nanobodies and their potential applications. Nanomedicine (2013) 8:1013-26. doi:10.2217/nnm.13.86

49. Muyldermans S, Baral TN, Retamozzo VC, De Baetselier P, De Genst E, Kinne J, et al. Camelid immunoglobulins and nanobody technology. Vet Immunol Immunopathol (2009) 128:178-83. doi:10.1016/j.vetimm.2008.10.299

50. Ewert S, Huber T, Honegger A, Plückthun A. Biophysical properties of human antibody variable domains. J Mol Biol (2003) 325:531-53. doi:10.1016/ S0022-2836(02)01237-8

51. Wang P, Li G, Yan J, Hu Y, Zhang C, Liu X, et al. Bactrian camel nanobody-based immunoassay for specific and sensitive detection of Cry1Fa toxin. Toxicon (2014) 92:186-92. doi:10.1016/j.toxicon.2014.10.024

52. Rodrigues JC, Godinho JL, de Souza W. Biology of human pathogenic trypanosomatids: epidemiology, lifecycle and ultrastructure. Subcell Biochem (2014) 74:1-42. doi:10.1007/978-94-007-7305-9

53. Caljon G, Van Den Abbeele J, Stijlemans B, Coosemans M, De Baetselier P, Magez S. Tsetse fly saliva accelerates the onset of Trypanosoma brucei infection in a mouse model associated with a reduced host inflammatory response. Infect Immun (2006) 74:6324-30. doi:10.1128/IAI.01046-06

54. Van Den Abbeele J, Caljon G, De Ridder K, De Baetselier P, Coosemans M. Trypanosoma brucei modifies the tsetse salivary composition, altering the fly feeding behavior that favors parasite transmission. PLoS Pathog (2010) 6:e1000926. doi:10.1371/journal.ppat.1000926

55. Caljon G, Van Reet N, De Trez C, Vermeersch M, Pérez-Morga D, Van Den Abbeele J. The dermis as a delivery site of Trypanosoma brucei for tsetse flies. PLoS Pathog (2016) 12:e1005744. doi:10.1371/journal.ppat. 1005744

56. Seed JR, Wenck MA. Role of the long slender to short stumpy transition in the life cycle of the African trypanosomes. Kinetoplastid Biol Dis (2003) 2:3. doi:10.1186/1475-9292-2-3

57. Mony BM, MacGregor P, Ivens A, Rojas F, Cowton A, Young J, et al. Genome-wide dissection of the quorum sensing signalling pathway in Trypanosoma brucei. Nature (2014) 505:681-5. doi:10.1038/nature12864

58. Rotureau B, Van Den Abbeele J. Through the dark continent: African trypanosome development in the tsetse fly. Front Cell Infect Microbiol (2013) 3:53. doi: $10.3389 /$ fcimb. 2013.00053

59. Sharma R, Gluenz E, Peacock L, Gibson W, Gull K, Carrington M. The heart of darkness: growth and form of Trypanosoma brucei in the tsetse fly. Trends Parasitol (2009) 25:517-24. doi:10.1016/j.pt.2009.08.001

60. Bringaud F, Riviere L, Coustou V. Energy metabolism of trypanosomatids: adaptation to available carbon sources. Mol Biochem Parasitol (2006) 149:1-9. doi:10.1016/j.molbiopara.2006.03.017

61. Natesan SK, Peacock L, Matthews K, Gibson W, Field MC. Activation of endocytosis as an adaptation to the mammalian host by trypanosomes. Eukaryot Cell (2007) 6:2029-37. doi:10.1128/EC.00213-07

62. Jones NG, Thomas EB, Brown E, Dickens NJ, Hammarton TC, Mottram JC. Regulators of Trypanosoma brucei cell cycle progression and differentiation identified using a kinome-wide RNAi screen. PLoS Pathog (2014) 10:e1003886. doi:10.1371/journal.ppat.1003886

63. Gruszynski AE, van Deursen FJ, Albareda MC, Best A, Chaudhary K, Cliffe LJ, et al. Regulation of surface coat exchange by differentiating African trypanosomes. Mol Biochem Parasitol (2006) 147:211-23. doi:10.1016/ j.molbiopara.2006.02.013

64. Matthews KR, Ellis JR, Paterou A. Molecular regulation of the life cycle of African trypanosomes. Trends Parasitol (2004) 20:40-7. doi:10.1016/j. pt.2003.10.016

65. Steverding D. Bloodstream forms of Trypanosoma brucei require only small amounts of iron for growth. Parasitol Res (1998) 84:59-62. doi:10.1007/ s004360050357
66. De Meyer T, Muyldermans S, Depicker A. Nanobody-based products as research and diagnostic tools. Trends Biotechnol (2014) 32:263-70. doi:10.1016/j.tibtech.2014.03.001

67. Pardon E, Laeremans T, Triest S, Rasmussen SG, Wohlkonig A, Ruf A, et al. A general protocol for the generation of nanobodies for structural biology. Nat Protoc (2014) 9:674-93. doi:10.1038/nprot.2014.039

68. Muyldermans S. Nanobodies: natural single-domain antibodies. Annu Rev Biochem (2013) 82:775-97. doi:10.1146/annurev-biochem-063011-092449

69. Lam AY, Pardon E, Korotkov KV, Hol WG, Steyaert J. Nanobody-aided structure determination of the EpsI:EpsJ pseudopilin heterodimer from Vibrio vulnificus. J Struct Biol (2009) 166:8-15. doi:10.1016/j.jsb.2008.11.008

70. Pathare GR, Nagy I, Śledź P, Anderson DJ, Zhou H-J, Pardon E, et al. Crystal structure of the proteasomal deubiquitylation module Rpn8-Rpn11. Proc Natl Acad Sci U S A (2014) 111:2984-9. doi:10.1073/pnas.1400546111

71. Holzmuller P, Grebaut P, Semballa S, Gonzatti MI, Geiger A. Proteomics: a new way to improve human African trypanosomiasis diagnosis? Expert Rev Proteomics (2013) 10:289-301. doi:10.1586/epr.13.14

72. Caljon G, Hussain S, Vermeiren L, Van Den Abbeele J. Description of a nanobody-based competitive immunoassay to detect tsetse fly exposure. PLoS Negl Trop Dis (2015) 9:e0003456. doi:10.1371/journal.pntd.0003456

73. Caljon G, Van Den Abbeele J, Sternberg JM, Coosemans M, De Baetselier P, Magez S. Tsetse fly saliva biases the immune response to Th2 and induces anti-vector antibodies that are a useful tool for exposure assessment. Int J Parasitol (2006) 36:1025-35. doi:10.1016/j.ijpara.2006.05.002

74. Saerens D, Stijlemans B, Baral TN, Nguyen Thi GT, Wernery U, Magez S, et al. Parallel selection of multiple anti-infectome nanobodies without access to purified antigens. J Immunol Methods (2008) 329:138-50. doi:10.1016/j. jim.2007.10.005

75. Yardehnavi N, Behdani M, Bagheri KP, Mahmoodzadeh A, Khanahmad H, Shahbazzadeh D, et al. A camelid antibody candidate for development of a therapeutic agent against Hemiscorpius lepturus envenomation. FASEB J (2014) 28:4004-14. doi:10.1096/fj.13-247478

76. Hassanzadeh-Ghassabeh G, Saerens D, Muyldermans S. Generation of anti-infectome/anti-proteome nanobodies. Methods Mol Biol (2011) 790:239-59. doi:10.1007/978-1-61779-319-6_19

77. Obishakin E, Stijlemans B, Santi-Rocca J, Vandenberghe I, Devreese B, Muldermans S, et al. Generation of a nanobody targeting the paraflagellar rod protein of trypanosomes. PLoS One (2014) 9:e115893. doi:10.1371/journal. pone. 0115893

78. Odongo S, Sterckx YG, Stijlemans B, Pillay D, Baltz T, Muyldermans S, et al. An anti-proteome nanobody library approach yields a specific immunoassay for Trypanosoma congolense diagnosis targeting glycosomal aldolase. PLoS Negl Trop Dis (2016) 10:e0004420. doi:10.1371/journal.pntd. 0004420

79. Dzakah EE, Kang K, Ni C, Wang H, Wu P, Tang S, et al. Plasmodium vivax aldolase-specific monoclonal antibodies and its application in clinical diagnosis of malaria infections in China. Malar J (2013) 12:199. doi:10.1186/1475-2875-12-199

80. Hutchinson OC, Webb H, Picozzi K, Welburn S, Carrington M. Candidate protein selection for diagnostic markers of African trypanosomiasis. Trends Parasitol (2004) 20:519-23. doi:10.1016/j.pt.2004.08.007

81. Stijlemans B, Conrath K, Cortez-Retamozo V, Van Xong H, Wyns L, Senter P, et al. Efficient targeting of conserved cryptic epitopes of infectious agents by single domain antibodies. African trypanosomes as paradigm. J Biol Chem (2004) 279:1256-61. doi:10.1074/jbc.M307341200

82. Jacobs RT, Nare B, Phillips MA. State of the art in African trypanosome drug discovery. Curr Top Med Chem (2011) 11:1255-74. doi:10.2174/ 156802611795429167

83. Vanhamme L, Paturiaux-Hanocq F, Poelvoorde P, Nolan DP, Lins L, Van Den Abbeele J, et al. Apolipoprotein L-I is the trypanosome lytic factor of human serum. Nature (2003) 422:83-7. doi:10.1038/nature01461

84. Lecordier L, Vanhollebeke B, Poelvoorde P, Tebabi P, PaturiauxHanocq F, Andris F, et al. C-terminal mutants of apolipoprotein L-I efficiently kill both Trypanosoma brucei brucei and Trypanosoma brucei rhodesiense. PLoS Pathog (2009) 5:e1000685. doi:10.1371/journal.ppat. 1000685

85. Baral TN, Magez S, Stijlemans B, Conrath K, Vanhollebeke B, Pays E, et al. Experimental therapy of African trypanosomiasis with a nanobody- 
conjugated human trypanolytic factor. Nat Med (2006) 12:580-4. doi:10.1038/ nm1395

86. Braddock M. Overcoming resistance with designer immunotoxins. Expert Opin Pharmacother (2006) 7:1409-12. doi:10.1517/14656566.7.10.1409

87. Barrett MP, Boykin DW, Brun R, Tidwell RR. Human African trypanosomiasis: pharmacological re-engagement with a neglected disease. $\mathrm{Br}$ J Pharmacol (2007) 152:1155-71. doi:10.1038/sj.bjp.0707354

88. Arias JL, Unciti-Broceta JD, Maceira J, Del Castillo T, HernándezQuero J, Magez S, et al. Nanobody conjugated PLGA nanoparticles for active targeting of African trypanosomiasis. JControl Release (2015) 197:190-8. doi:10.1016/j.jconrel.2014.11.002

89. Garcia-Salcedo JA, Unciti-Broceta JD, Soriano M. Could specific cell targeting overcome resistance associated with current treatments for African trypanosomiasis? Nanomedicine (Lond) (2015) 10(24):3515-7. doi:10.2217/ nnm.15.167

90. Garcia-Salcedo JA, Unciti-Broceta JD, Valverde-Pozo J, Soriano M. New approaches to overcome transport related drug resistance in trypanosomatid parasites. Front Pharmacol (2016) 7:351. doi:10.3389/fphar.2016.00351

91. Baker N, Glover L, Munday JC, Aguinaga Andres D, Barrett MP, de Koning HP, et al. Aquaglyceroporin 2 controls susceptibility to melarsoprol and pentamidine in African trypanosomes. Proc Natl Acad Sci U S A (2012) 109:10996-1001. doi:10.1073/pnas.1202885109

92. Song J, Baker N, Rothert M, Henke B, Jeacock L, Horn D, et al. Pentamidine is not a permeant but a nanomolar inhibitor of the Trypanosoma brucei aquaglyceroporin-2. PLoS Pathog (2016) 12(2):e1005436. doi:10.1371/ journal.ppat.1005436

93. Caljon G, Caveliers V, Lahoutte T, Stijlemans B, Ghassabeh GH, Van Den Abbeele J, et al. Using microdialysis to analyse the passage of monovalent nanobodies through the blood-brain barrier. Br JPharmacol (2012) 165:2341-53. doi:10.1111/j.1476-5381.2011.01723.x

94. Iqbal U, Trojahn U, Albaghdadi H, Zhang J, O'Connor-McCourt M, Stanimirovic D, et al. Kinetic analysis of novel mono- and multivalent VHHfragments and their application for molecular imaging of brain tumours. Br J Pharmacol (2010) 160:1016-28. doi:10.1111/j.1476-5381.2010.00742.x

95. Saerens D, Pellis M, Loris R, Pardon E, Dumoulin M, Matagne A, et al. Identification of a universal $\mathrm{VHH}$ framework to graft non-canonical antigen-binding loops of camel single-domain antibodies. J Mol Biol (2005) 352:597-607. doi:10.1016/j.jmb.2005.07.038

96. Vaneycken I, Govaert J, Vincke C, Caveliers V, Lahoutte T, De Baetselier P, et al. In vitro analysis and in vivo tumor targeting of a humanized, grafted nanobody in mice using pinhole SPECT/micro-CT. J Nucl Med (2010) 51:1099-106. doi:10.2967/jnumed.109.069823

97. Zoltner M, Horn D, de Koning HP, Field MC. Exploiting the Achilles' heel of membrane trafficking in trypanosomes. Curr Opin Microbiol (2016) 34:97-103. doi:10.1016/j.mib.2016.08.005

98. Stijlemans B, Caljon G, Natesan SK, Saerens D, Conrath K, PérezMorga D, et al. High affinity nanobodies against the Trypanosoma brucei VSG are potent trypanolytic agents that block endocytosis. PLoS Pathog (2011) 7(6):e1002072. doi:10.1371/journal.ppat.1002072

99. Field MC, Carrington M. The trypanosome flagellar pocket. Nat Rev Microbiol (2009) 7:775-86. doi:10.1038/nrmicro2221

100. Manna PT, Obado SO, Boehm C, Gadelha C, Sali A, Chait BT, et al. Lineagespecific proteins essential for endocytosis in trypanosomes. J Cell Sci (2017) 130(8):1379-92. doi:10.1242/jcs.191478

101. Salmon D, Geuskens M, Hanocq F, Hanocq-Quertier J, Nolan D, Ruben L, et al. A novel heterodimeric transferrin receptor encoded by a pair of VSG expression site-associated genes in T. brucei. Cell (1994) 78:75-86. doi:10.1016/0092-8674(94)90574-6

102. Holland MC, Wurthner JU, Morley PJ, Birchler MA, Lambert J, Albayaty M, et al. Autoantibodies to variable heavy $(\mathrm{VH})$ chain Ig sequences in humans impact the safety and clinical pharmacology of a $\mathrm{VH}$ domain antibody antagonist of TNF- $\alpha$ receptor 1. J Clin Immunol (2013) 33:1192-203. doi:10.1007/ s10875-013-9915-0

103. Papadopoulos KP, Isaacs R, Bilic S, Kentsch K, Huet HA, Hofmann M, et al. Unexpected hepatotoxicity in a phase I study of TAS266, a novel tetravalent agonistic Nanobody ${ }^{\circledR}$ targeting the DR5 receptor. Cancer Chemother Pharmacol (2015) 75:887-95. doi:10.1007/s00280-015-2712-0

104. Keyaerts M, Xavier C, Heemskerk J, Devoogdt N, Everaert H, Ackaert C, et al. Phase I study of 68Ga-HER2-nanobody for PET/CT assessment of
HER2 expression in breast carcinoma. J Nucl Med (2016) 57:27-33. doi:10.2967/jnumed.115.162024

105. Bartunek J, Barbato E, Heyndrickx G, Vanderheyden M, Wijns W, Holz JB. Novel antiplatelet agents: ALX-0081, a nanobody directed towards von Willebrand factor. JCardiovasc Transl Res (2013) 6:355-63. doi:10.1007/ s12265-012-9435-y

106. Steeland S, Vandenbroucke RE, Libert C. Nanobodies as therapeutics: big opportunities for small antibodies. Drug Discov Today (2016) 21:1076-113. doi:10.1016/j.drudis.2016.04.003

107. Cortez-Retamozo V, Lauwereys M, Hassanzadeh Gh G, Gobert M, Conrath K, Muyldermans S, et al. Efficient tumor targeting by single-domain antibody fragments of camels. Int J Cancer (2002) 98:456-62. doi:10.1002/ ijc. 10212

108. Coppieters K, Dreier T, Silence K, de Haard H, Lauwereys M, Casteels P, et al. Formatted anti-tumor necrosis factor alpha $\mathrm{VHH}$ proteins derived from camelids show superior potency and targeting to inflamed joints in a murine model of collagen-induced arthritis. Arthritis Rheum (2006) 54:1856-66. doi:10.1002/art.21827

109. Vincke C, Loris R, Saerens D, Martinez-Rodriguez S, Muyldermans S, Conrath K. General strategy to humanize a camelid single-domain antibody and identification of a universal humanized nanobody scaffold. J Biol Chem (2009) 284:3273-84. doi:10.1074/jbc.M806889200

110. De Vooght L, Caljon G, Stijlemans B, De Baetselier P, Coosemans M, Van den Abbeele J. Expression and extracellular release of a functional anti-trypanosome Nanobody ${ }^{\circledR}$ in Sodalis glossinidius, a bacterial symbiont of the tsetse fly. Microb Cell Fact (2012) 11:23. doi:10.1186/1475-2859-11-23

111. De Vooght L, Caljon G, De Ridder K, Van Den Abbeele J. Delivery of a functional anti-trypanosome nanobody in different tsetse fly tissues via a bacterial symbiont, Sodalis glossinidius. Microb Cell Fact (2014) 13:156. doi:10.1186/ s12934-014-0156-6

112. Caljon G, De Vooght L, Van Den Abbeele J. Options for the delivery of anti-pathogen molecules in arthropod vectors. J Invertebr Pathol (2013) 112(Suppl):S75-82. doi:10.1016/j.jip.2012.07.013

113. De Vooght L, Caljon G, Van Hees J, Van Den Abbeele J. Paternal transmission of a secondary symbiont during mating in the viviparous tsetse fly. Mol Biol Evol (2015) 32:1977-80. doi:10.1093/molbev/msv077

114. Harmsen MM, Van Solt CB, Van Zijderveld-Van Bemmel AM, Niewold TA, Van Zijderveld FG. Selection and optimization of proteolytically stable llama single-domain antibody fragments for oral immunotherapy. Appl Microbiol Biotechnol (2006) 72:544-51. doi:10.1007/s00253-005-0300-7

115. Caljon G, Stijlemans B, Saerens D, van den Abbeele J, Muyldermans S, Magez S, et al. Affinity is an important determinant of the anti-trypanosome activity of nanobodies. PLoS Negl Trop Dis (2012) 6:e1902. doi:10.1371/ journal.pntd.0001902

116. Dean SD, Matthews KR. Restless gossamers: antibody clearance by hydrodynamic flow forces generated at the surface of motile trypanosome parasites. Cell Host Microbe (2007) 2:279-81. doi:10.1016/j.chom.2007. 10.006

117. Engstler $M$, Pfohl $T$, Herminghaus $S$, Boshart M, Wiegertjes $G$, Heddergott $\mathrm{N}$, et al. Hydrodynamic flow-mediated protein sorting on the cell surface of trypanosomes. Cell (2007) 131:505-15. doi:10.1016/j. cell.2007.08.046

118. Cnops J, Magez S, De Trez C. Escape mechanisms of African trypanosomes: why trypanosomosis is keeping us awake. Parasitology (2015) 142:417-27. doi:10.1017/S0031182014001838

119. Bruschi F, Chiumiento L. Immunomodulation in trichinellosis: does Trichinella really escape the host immune system? Endocr Metab Immune Disord Drug Targets (2012) 12:4-15. doi:10.2174/187153012799279081

120. Stijlemans B, Caljon G, Van Den Abbeele J, Van Ginderachter JA, Magez S, De Trez C. Immune evasion strategies of Trypanosoma brucei within the mammalian host: progression to pathogenicity. Front Immunol (2016) 7:233. doi:10.3389/fimmu.2016.00233

121. Schwede A, Macleod OJ, MacGregor P, Carrington M. How does the VSG coat of bloodstream form African trypanosomes interact with external proteins? PLoS Pathog (2015) 11:e1005259. doi:10.1371/journal. ppat. 1005259

122. Jackson DG, Owen MJ, Voorheis HP. A new method for the rapid purification of both the membrane-bound and released forms of the variant surface 
glycoprotein from Trypanosoma brucei. Biochem J (1985) 230:195-202. doi:10.1042/bj2300195

123. Schwede A, Jones N, Engstler M, Carrington M. The VSG C-terminal domain is inaccessible to antibodies on live trypanosomes. Mol Biochem Parasitol (2011) 175:201-4. doi:10.1016/j. molbiopara.2010.11.004

124. Engstler M, Thilo L, Weise F, Grünfelder CG, Schwarz H, Boshart M, et al. Kinetics of endocytosis and recycling of the GPI-anchored variant surface glycoprotein in Trypanosoma brucei. J Cell Sci (2004) 117:1105-15. doi: $10.1242 /$ jcs. 00938

125. Wentworth P Jr, McDunn JE, Wentworth AD, Takeuchi C, Nieva J, Jones $\mathrm{T}$, et al. Evidence for antibody-catalyzed ozone formation in bacterial killing and inflammation. Science (2002) 298:2195-9. doi:10.1126/ science. 1077642

126. Wentworth P Jr, Jones LH, Wentworth AD, Zhu X, Larsen NA, Wilson IA, et al. Antibody catalysis of the oxidation of water. Science (2001) 293:1806-11. doi:10.1126/science. 1062722
127. Wentworth AD, Jones LH, Wentworth P, Janda KD, Lerner RA. Antibodies have the intrinsic capacity to destroy antigens. Proc Natl Acad Sci U S A (2000) 97:10930-5. doi:10.1073/pnas.97.20.10930

128. Yan B, Yates Z, Balland A, Kleemann GR. Human IgG1 hinge fragmentation as the result of $\mathrm{H}_{2} \mathrm{O}_{2}$-mediated radical cleavage. J Biol Chem (2009) 284:35390-402. doi:10.1074/jbc.M109.064147

Conflict of Interest Statement: The authors declare that the research was conducted in the absence of any commercial or financial relationships that could be construed as a potential conflict of interest.

Copyright $\odot 2017$ Stijlemans, De Baetselier, Caljon, Van Den Abbeele, Van Ginderachter and Magez. This is an open-access article distributed under the terms of the Creative Commons Attribution License (CC BY). The use, distribution or reproduction in other forums is permitted, provided the original author(s) or licensor are credited and that the original publication in this journal is cited, in accordance with accepted academic practice. No use, distribution or reproduction is permitted which does not comply with these terms. 